\title{
Correspondence
}

\section{Ventilator settings and active expiration}

Sir,

We read with interest the paper by Field et al reporting an attempt to manipulate ventilator settings to prevent active expiration against positive pressure inflation.' We have previously shown how disastrous such an interaction can be and as a consequence feel that any manoeuvre designed to try and lessen the incidence of this condition must be applauded. ${ }^{2}$ For such techniques to be successful, however, an increased understanding of the aetiology of this condition is necessary. Unfortunately, the variety of ventilator settings of the eight infants actively expiring in the study by Field et al (peak pressures 12-28 $\mathrm{cm} \mathrm{H}_{2} \mathrm{O}$, positive end expiratory pressure $0-3 \mathrm{~cm} \mathrm{H}_{2} \mathrm{O}$, inspiratory time $0 \cdot 4-1 \cdot 0$ second, ventilator rate $45-100$ per minute) make it difficult to draw conclusions regarding their individual roles in provoking this reflex.

Our original description of active expiration was at 'conventional' frequencies of $30-40 / \mathrm{min}$ with an inspiratory to expiratory (I:E) ratio of $1: 1$ (in the presence of blood gases within the desired range), and we noted in that study that at higher frequencies infants tended to breath in synchrony with their ventilators or be apnoeic. ${ }^{3}$ In the study of Field et al higher frequencies also were successful in preventing active expiration in four of the eight infants included in their study. ${ }^{1}$ We feel we should stress, however, that it is important not to draw conclusions that fast rates always result in reducing the incidence of active expiration. We have recently shown in a controlled study, including 17 infants, all actively expiring at conventional frequencies $(30-40 / \mathrm{min}, I: E$ ratio $1: 1)$, that in only approximately half were the infants rates of 60 and 120 breaths/min successful at suppressing active expiration. We also found in that study that at the higher rates (unlike our experience at conventional frequencies) infants change their pattern of interaction and in certain cases reverted back to active expiration after a period of synchronous breathing at the faster rates. ${ }^{4}$ We concluded that fast rates were therefore only successful in certain infants in prevention of active expiration, and even in those infants continuous or frequent recordings would be necessary to ensure that the disastrous reflex-that is, active expiration -had not recurred, putting the infant again at risk of an air leak.

Field $e t$ al's study indicated that I:E ratios may also be important in the aetiology of active expiration, a 'physiological $I: E$ ratio in their study being apparently less detrimental, but in two of their eight cases of active expiration neither a change of rate nor $\mathrm{I}: \mathrm{E}$ ratio was successful in preventing this reflex. 'Artificial ventilation is made up of many features-positive end expiratory pressure, positive inspiratory pressure, I:E ratio, ventilator rate, flow, type of ventilator, etc. To give clearer guide- lines about a pattern of ventilation that may avoid active expiration, we would suggest that a systematic investigation, which we have undertaken and hope to report in the near future, may be more successful.

Anne Grennough King's College Hospital, London SE5 8RX, and COLIN MoRLey Addenbrooke's Hospital, Cambridge

Sir,

We read with interest Field et al's paper concerning prevention of active expiration against positive pressure inflation by manipulation of ventilator settings. ${ }^{1}$ They add a sixth category of interaction to those described ${ }^{5}$ and give an example of this, showing a period of ventilation lasting 12 seconds. Four episodes occur during which spontaneous expiration happens during ventilator inflation. As five or more episodes in 30 seconds is one of their criteria for $\mathscr{O}$ active expiration, it is not clear that this 'mixed' interaction group are separate and at lower risk of pneumothorax. The classification of baby-ventilator interaction requires further study, but we do not feel that the addition of this 'mixed' group is contributory.

This study, in a selected group of neonates, compares the effects of an incomplete series of changes between arbitrarily chosen ventilator time settings in a nonrandomised sequence.

The paper seems to show that active expiration against the ventilator is less likely with faster ventilator rates, or low inspiratory to expiratory (I:E) ratios, than slower rates, or high $\mathrm{I}: \mathrm{E}$ ratios. Common to both fast rates and low $\mathrm{I}: \mathrm{E}$ ratios is a short inspiratory time, and this may be the reason for a reduction in active expiration in this study. In our studies babies with respiratory distress syndrome breathe with inspiratory times of $0.24-0.4$ seconds. It is when ventilator inflations last longer than the babies' own 'intrinsic' inspiratory time that active expiration against the ventilator may occur.

In Field el al's study babies from 24 to 40 weeks' gestation, from a few hours to 7 days of age, and with $\mathrm{N}$ respiratory distress syndrome of variable severity were all $\Omega$ grouped together. Spontaneous respiratory times vary with $\mathrm{N}$ a number of factors-that is, gestation, postnatal age," and $\mathrm{N}$ severity of respiratory distress syndrome. These times vary $\omega$ as respiratory time constants change with the course of the respiratory illness. To prevent active expiration against the ventilator, time settings may need to be adjusted individually and possibly changed with time.

The paper mentions the use of 'physiological' I:E ratios. T We do not know what I:E ratios are 'physiological' in intubated premature babies with respiratory distress syndrome. 